\title{
Strategic actions of urban development to define the intervention policies of slums
}

\author{
Amany Ragheb* (D) and Rasha El-Ashmawy
}

\begin{abstract}
The problem of slums is one of the most imperative problems experienced by many developing countries as well as some developed countries. The random gatherings shape real disruption in the economic and social development plans of the concerned countries. The importance of the research lies in conducting a field study for Ezbet El-Shahatin area in Mansoura city, given that it is the largest unplanned informal area in Dakahlia Governorate in terms of area. Geographic information systems were used to make enter data to form a coordinated database. In addition, policy intervention matrix in slums was used to make the appropriate decision regarding the development of the area. The study concludes to specifying several recommendations to deal with slums and set a model for integrated urban development in low-income areas that can be repeated in other similar locations.
\end{abstract}

Keywords: Mansoura city, Ezbet El-Shahatin, Slums Area, Sustainable urban development; developing countries, Policy intervention matrix

\section{Introduction}

Slums are unplanned residential areas that were not included in the urban planning of the zoned areas of cities (Khalifa 2011). They originated without planning due to officials negligence. They are located anywhere and in any form, on agricultural or space land, inside or outside the cities, on desert land, and the banks of lakes and rivers (Parham 2012). They can be erected in areas that are difficult to build, such as hills, mountains, valleys, and quarries. Moreover, they can be built on lands with legal ownership, such as random subdivisions of agricultural areas, or on lands with illegal ownership, such as adverse possession on the state's property (UN-Habitat 2015).

The problem of slums is one of the most important problems that developing countries and some developed countries suffer from, notwithstanding the different dimensions of the problem (Ezeh et al. 2017). Due to the growing magnitude of this problem and its serious repercussions during the past three decades in Egypt, it

\footnotetext{
*Correspondence: raghebamany@yahoo.com

Department of Architectural, Faculty of Engineering, Delta University for Science and Technology, International Coastal Road, Gamasa city, Mansoura, Dakhliya, Egypt
}

has become one of the urgent issues that need a comprehensive confrontation to limit its spread and address its negative impacts.

In addition, the population explosion expresses a real disruption in the plans of economic and social development and an imbalance in urban planning (McCombie 2016), where the phenomenon of random gatherings is linked to the phenomenon of urban marginalization, in addition to being considered foci of extremism and crime (Crețan 2019).

It should be borne in mind that slums will not be confronted through short plans that depend on the relocation of slums residents to alternative housing units (Gans 1959); however, slums will be handled through a longterm strategy in which the ministries of housing (Jones 2017), utilities, urban development, agriculture, irrigation, and water resources are involved, and which is mainly dependent on the urban development of Egypt as a whole.

The Egyptian government developed a set of approaches and legislations to mitigate or stop the growth of slums. Nonetheless, successes in improving or removing these areas were limited to specific communities. 
Regarding Slum Development Fund projects in provincial capitals, such as the Asmarat Project and Beshir al-Khair Project, the Fund is searching for a land area of less than 5 acres, on which there is an integrated project with multiple housing levels and residents are compensated by the Central Agency for Public Mobilization and Statistics 2020.

This study is based on the government's approach toward informal areas in addition to exploring the difference between the responses of the poor slum model (Shepherd et al. 2020), giving an example of each. It discusses how the informal form has reshaped the form and nature of the Egyptian cities over the past several decades. It is an issue of interest to researchers in the relevant fields.

The manuscript was carried out by researchers according to a mega research project funded by Delta University for Science and Technology as one of the university's community service projects.

The research aims to learn about the classification of slums in Egypt and the strategies for developing those areas, and check the stages of preparing an action plan for the slum development project and conducting a field study for Ezbet El-Shahatin area in Mansoura, given that it is the largest unplanned informal area in Dakahlia Governorate in terms of area.

Geographic information systems were used to collect and enter data for random areas to form a coordinated database and specify several recommendations to deal with slums.

The main result of the study is learning from these exemplary responses to improve the quality of life and public health in informal areas. Through experiences that have occurred on slums, several recommendations can be defined to develop slums, which will create a balanced and sustainable master plan for sensitive development and set a model for integrated urban development in low-income areas that is replicable in other similar locations.

\section{Theoretical background}

At an Expert Group Meeting in November 2002, UNHABITAT, partners produced a provisional definition of a "slum". It is a settlement in an urban region in which more than half of the occupants live in insufficient lodging and lack basic services. Creating an operational definition-one with measurable indicators-it required further refinement, recognizing that slums can be geographically coterminous or isolated units. UN-HABITAT: therefore, focuses on the household as the essential unit of analysis. These expressive qualities make enthusiastic changes along with the behavior designs of human beings (UN-HABITAT 2003a, b).

In addition, the slum household could be a bunch of people living beneath the same roof in an urban zone who lack one or more of the following five conditions: durable housing-enough living area-access to improved water-access to sanitation-secure tenure.

Furthermore, there is an Egyptian term to informal areas which is "Ashwaeyat". It is the only one used officially to indicate deteriorated or under-served urban zones. It means "random", implying that these regions are unplanned and illegally built. In this way they are not necessarily slums. Although being informal/illegal, they tend to be at slightest well served in terms of infrastructure and public services as they endure poor accessibility and high levels of overcrowding. The scope of settlement sorts is complex within the context and variety of equivalent words in other languages and geographical districts, such as Favelas, Kampungs and Boonville's.

Informal development has been, and proceeds to be, the dominant mode of urbanization in a lot of developing countries, including Egypt. It happens especially on the urban fringes, on privately-owned agricultural land, instead of in desert areas which would be considered hunching down on state-owned land. The following is an explanation of the causes and motives for the formation of slums (Table 1).

Furthermore, the reasons of emergence of slums can be enumerated as: high urbanization rate, urban

Table 1 Reasons for the emergence of slums

Compulsive motives

Economic motives

Investment motives
Citizens are forced to resort to slum lodgings, as in cases of earthquakes, disasters, and house collapses which forces residents to erect wooden or tin stalls next to the lodgings that have been destroyed or cleared. Besides, some residents may resort to lodging tombs or establish camps on the outskirts of cities without state intervention until a house is arranged (Pelz et al. 2019)

It is the internal migration from the original home to a new one in pursuit of livelihood (Pelz et al. 2019)

Squatters divide the land space and sell it in order to achieve quick gains. In addition, some farmers who own agricultural land on the outskirts of the urban blocs bulldoze their lands and sell the silt layer to the red brick factories, then sell the lands to an investor to divide them into small pieces and sell them. Thus, the agricultural land is gradually transformed into a slum area (Fig. 1). These lands are not often planned or prepared as a residential community 
poverty, lack of urban planning, complex urban land tenure systems, extension of boundaries of urban centers, the effect of decentralization and poor urban centers (Fig. 1).

Informality became the solution to the housing needs of the city's lower and middle classes. It is estimated that the total area of the urban clusters of Egypt is 417024.3 acres, and the total area of slum areas is $160,806.8$ acres, meaning that the percentage of slums from the urban cluster is $38.6 \%$, (according to Central Agency for Public Mobilization and Statistics agency 2020).
According to location, there are four fundamental types of slums which are informal Settlements on Former Agricultural Land, Informal Areas on Former Desert State Land, Deteriorated Historic Core and Deteriorated Urban Pockets (Khalifa 2015). However, according to situation (Fig. 2), there are two fundamental types of slums which are Unsafe areas and unplanned areas (Table 2).

In recent times, $87.4 \%$ of the unsafe areas on the national map have been completed, the country has 357 unsafe slum areas, 312 areas have been developed, and the remaining 45 areas are currently being worked on. Unplanned areas are being worked on in parallel with the

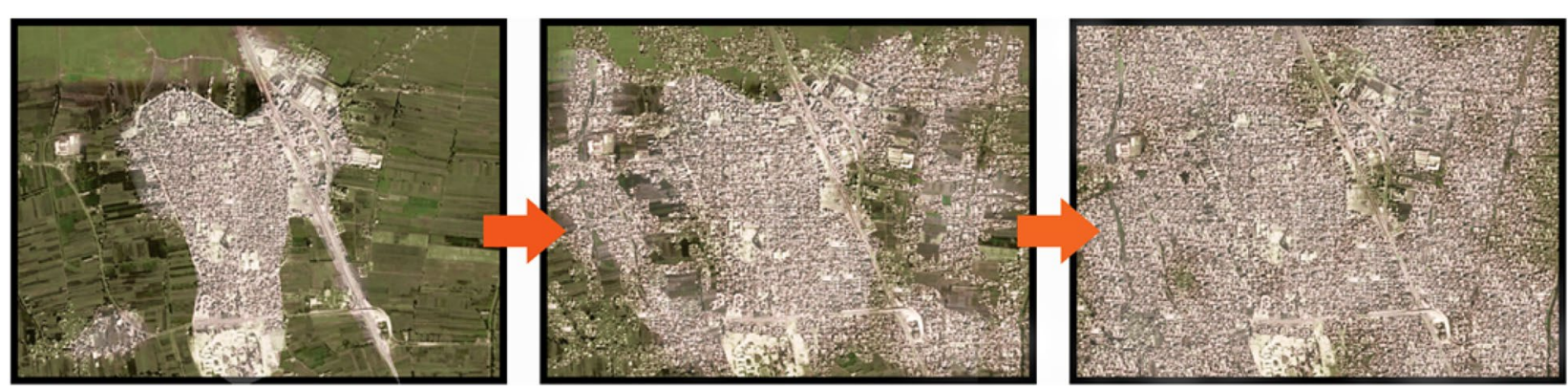

Fig. 1 Gradual encroachments on agricultural lands (researcher)

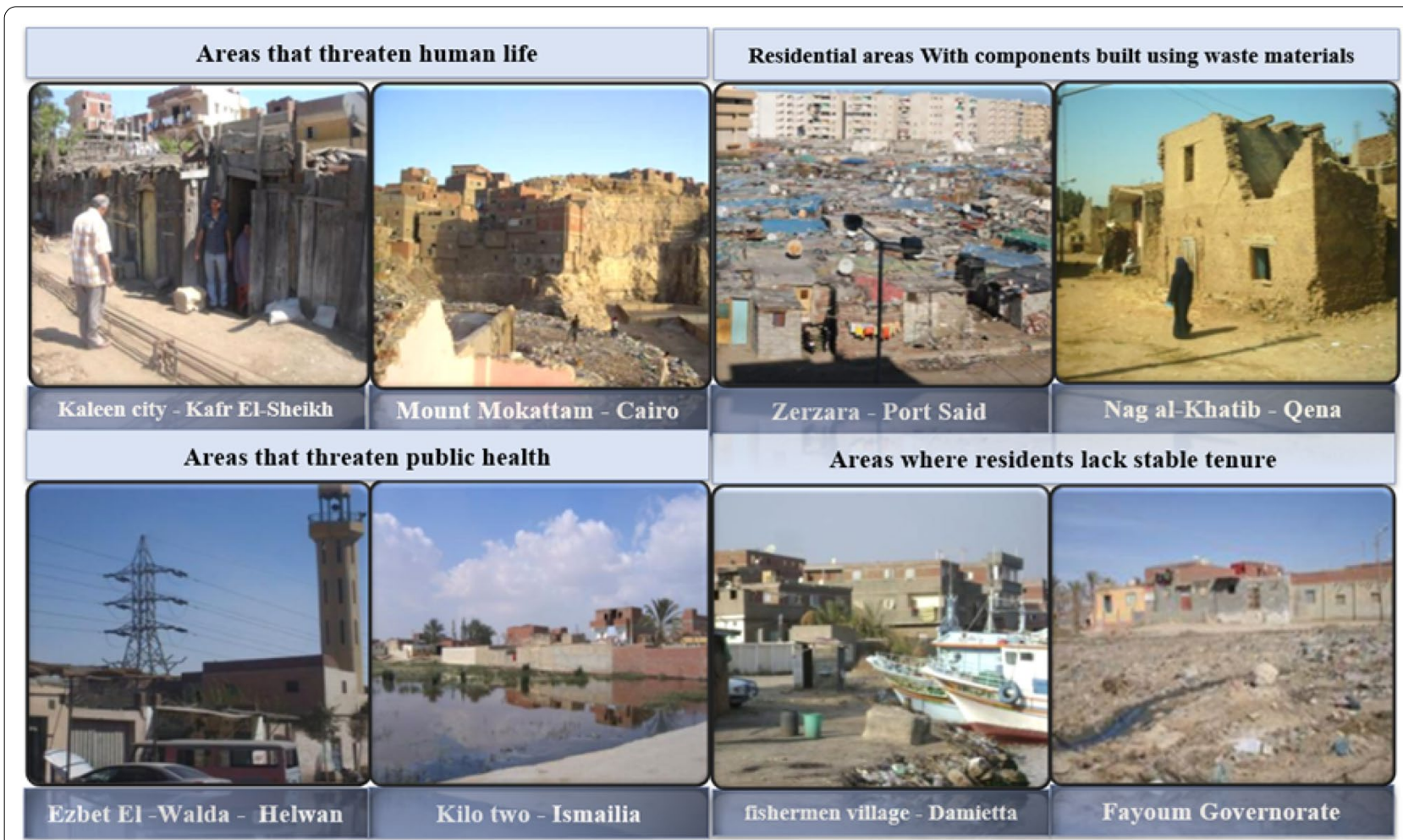

Fig. 2 classification of slums ( Source: Presidency of the Council of Ministers Slums Development Fund) 
Table 2 Types of slums in Egypt (according to Central Agency for Public Mobilization and Statistics agency 2020)

\begin{tabular}{lll}
\hline Type & Unsafe areas & Unplanned areas \\
\hline Density & $60 \%$ of the urban mass 200 people/acre & $60 \%$ of the urban population people/acre \\
Building heights & $1-2$ floors & $2-14$ floors \\
Housing & No safe housing & A minimum of safe housing \\
Intervention & Requires immediate critical intervention & Requires medium and long-term development \\
\hline
\end{tabular}

unsafe areas. $77 \%$ areas have been completed in the cities of Egypt, but there are still a lot of unplanned areas that need more work according to Central Agency for Public Mobilization and Statistics agency 2021.

The strategy of dealing with slums implies that the state has complete data on the size of the problem (Rankey 2018) so that it can manage and employ the available resources and capabilities successfully (Fig. 2). In addition, the state should have the ability to define development mechanisms and determine the policy of intervention and priorities, in respect with the laws and regulations (Table 3).

\section{Model responses}

Intervention policies depend on the availability of the desire of the population for a better life, the existence of a sound management organization among all participants and beneficiaries, giving full powers to the body that organizes the development process in addition to providing all the necessary funds.

According to the World Bank, 2006, there are three typical responses to slums in urban areas which are
Forced Evictions and Relocation, Clearance and on-site redevelopment, and Comprehensive Upgrading in place (Atlaw 2014).

\section{A. Forced evictions and relocation}

This is a method of radical change in the urban environment, which is complete eviction, resettlement, and replacement, where the region is completely cleared. This method is preferable to use only in the narrowest limits and for strong reasons due to its economic and social problems. This is done in the underdeveloped areas inhabited by families suffering from minimum living conditions such as stalls areas or other dilapidated housing or environmentally and urban inconsistent occupations characterized by (UN-HABITAT 2003a, b).

- The number of residents' permits moving and finding alternative housing.

- High crowding rate and more than one family in one house.

- Lack of basic facilities such as water, sewage, electricity, and the difficulty of providing them.

Table 3 Criteria for classification of slums and the mechanisms for dealing with them

\begin{tabular}{|c|c|c|}
\hline Classification & Description & Dealing mechanisms \\
\hline Areas that threaten human life & $\begin{array}{l}\text { Areas prone to slipping of stone blocks from the } \\
\text { mountains } \\
\text { Torrential areas } \\
\text { Areas prone to rail accidents }\end{array}$ & $\begin{array}{l}\text { Residents are transferred immediately to housing units } \\
\text { or paid a financial compensation }\end{array}$ \\
\hline Residential areas & $\begin{array}{l}\text { With components built using waste materials } \\
\text { With destroyed or cracked facilities } \\
\text { Built on landfills } \\
\text { Land on private property (different) }\end{array}$ & $\begin{array}{l}\text { Replacing housing on site with intensification } \\
\text { Building housing in other nearby locations (state } \\
\text { properties) } \\
\text { Financial compensation for housing provision } \\
\text { Rehabilitation of housing } \\
\text { Removing damaged buildings at the owner's expense } \\
\text { Providing building development loans }\end{array}$ \\
\hline Areas that threaten public health & $\begin{array}{l}\text { Lack of clean water or improved sanitation } \\
\text { Under the influence of heavy industrial pollution } \\
\text { Originated under the overhead power lines }\end{array}$ & $\begin{array}{l}\text { Transferring or converting overhead electrical lines to } \\
\text { ground cables } \\
\text { Adjusting the conditions of factories polluting the } \\
\text { environment } \\
\text { Implementing safe water and sewage systems }\end{array}$ \\
\hline Areas where residents lack stable tenure & $\begin{array}{l}\text { The lands are divided into: } \\
\text { Territories on state lands } \\
\text { Territories on lands dominated by central authorities } \\
\text { Areas on the endowment lands }\end{array}$ & $\begin{array}{l}\text { Legalization of tenure in exchange for money } \\
\text { Providing alternative housing }\end{array}$ \\
\hline
\end{tabular}


- Houses are difficult to fit for any improvement or development.

- Streets are narrow and winding, making it difficult to face major problems such as fire.

- Housing closeness which results in poor ventilation, poor health, and high mortality.

- Security problems and the high rate of homelessness and criminality.

- Lack of privacy.

- The environmental risk of uncontrollable pollution.

There are other criteria that influence decision-making regarding the eviction such as the flat area, ownership, building heights, level, and the basic services available in relation to health and education... etc.

\section{B. Clearance and on-site redevelopment}

Slum clearance or slum evacuation is an urban renewal strategy utilized to convert low-income settlements with poor reputation into another sort of development or lodging. This has long been a strategy for redeveloping urban communities. Slum redevelopment is an urban renewal strategy which consists of a demolition of slums, embraced cooperatively by massive organizations, to form a way for hotels and different other buildings (Young 2016).

It is a method that deals with informal areas from the urban side which leads to the development and improvement of its condition. It includes repair and renewal and is suitable for medium buildings in order to prevent their deterioration. It is a method for developing sites and services and deals with slums that are adjacent to empty lands by providing the planned future extension. It is based on the participation of both the state and the population, so the state provides sites, divides them, equips them with services and facilities and sells them, provided that the residents design and build housing on their own.

Rehousing is an approach to human settlements in which the government temporarily houses a community off-site, clears an existing settlement and builds new apartments on the same land that are given to the original residents (Lutzoni 2016).

\section{Comprehensive upgrading in place}

Upgrading is widely considered an international best practice for improving slums. It minimizes the direct effect on the nearby economy and, for the most part, clears out communities intact. It is less expensive than either rehousing or relocation and can make a quick, exceedingly visible improvement in communities. (Upgrading is additionally perfect way) the most efficient way to ensure that the targeted community really benefits from the project and it can mobilize local investment or attract exterior investment (Somsook 2009).

It is a comprehensive method that deals with slums in all urban, environmental, economic, and social aspects to improve its condition and develop it gradually. It is the method of upgrading, which involves other methods such as eviction, gradual replacement, repair and redevelopment (Bah et al. 2018).

There are three main stages of upgrading an informal settlement:

- Primary level services which address a community's basic health needs.

- Intermediate level services which are socially and culturally accepted levels of service.

- Ultimate level services which are those services that are provided for the convenience of residents.

\section{Action plan for developing slums}

\section{The stages of preparing an action plan}

Slum's development projects depend on adequate studies of the target community to identify the potentials, problems, and shortcomings to determine the desired priorities for development. Then, the goals required to achieve the priorities are set in cooperation with the participating agencies in the form of workshops (Table 4) to come out with the initial alternatives that end up with the preparation of the most realistic projects.

To ensure the project's efficiency, setting a specific management program is required, through which responsibilities, timeframes and due funding are determined. This is followed by the implementation phase and concerted efforts to complete the program. To ensure the effectiveness of those stages, follow-up and maintenance are required in parallel with all these stages to ensure the sustainability and continuity of the projects. These stages are considered the effective implementation framework for the slum's development projects.

\section{Matrix defining the intervention policy}

The criteria related to taking the decision to remove or develop the area include the housing situation in the region, the number, density and characteristics of its population, the extent of the deterioration of the infrastructure, the extent and breadth of the streets, the extent of the existence of basic services in the region, etc. It also depends on the location of the slum area in the city (on the outskirts-in the city center), the importance of the slum area and its economic value in the event of its clearance and re-planning on architectural and urban grounds, the need to open new traffic axes, 
Table 4 The main stages of slum development projects

\begin{tabular}{|c|c|}
\hline The main stages of slum develop & ent projects \\
\hline Prioritization phase & $\begin{array}{l}\text { A detailed study of the characteristics and basic needs of the target community } \\
\text { A detailed study of the site's features (urban inventory_-socio-economic inventory)_identification of problems }\end{array}$ \\
\hline Project formulation & Setting goals_-setting alternatives_identifying projects \\
\hline Setting the administrative program & Allocating responsibilities_-setting the time plan \\
\hline Implementation phase & $\begin{array}{l}\text { Pooling the efforts of the participating agencies-adherence to the specified timetable } \\
\text { Ensuring the integration of material and human resources_encouraging and supporting community partici- } \\
\text { pation of the target groups } \\
\text { Using technical assistance of experts during implementation_-the coordinating administrative body notes } \\
\text { developments and tries to find solutions } \\
\text { Ensuring continuity and ease of implementation by coordinating relations between the various participating } \\
\text { bodies and mobilizing their efforts and capabilities }\end{array}$ \\
\hline Follow-up and maintenance & $\begin{array}{l}\text { Follow-up of the proposed schedule and its conformity with reality to measure its effectiveness and reconsider } \\
\text { its formulation } \\
\text { Follow-up to the estimated costs and the extent of their adaptability of the new continuous changes, in addi- } \\
\text { tion to reconsidering the development of funding resources to meet the needs } \\
\text { Preparing periodic reports prepared by advisory, administrative and people bodies that reflect their vision of the } \\
\text { extent of development stages of preparation and implementation, and the extent of work progress to assess } \\
\text { the extent of benefit from what has been done and how to develop it } \\
\text { A future view of the interests of the others and the right of future generations to enjoy what has been accom- } \\
\text { plished } \\
\text { Follow-up to the extent of benefiting from local resources-follow how the decision is taken and how compre- } \\
\text { hensive it is for all development partners }\end{array}$ \\
\hline
\end{tabular}

and alternative solutions available to do the development through such clearance (In our previous study Ragheb et al. 2016).

If the region has investment potential, high economic returns and developed performance of the city services, there would be a tendency to clear and redesign it. On the contrary, when its impact is marginal and the conditions of buildings, streets and facilities allow development, it would be developed. Therefore, a matrix may be relied on to determine Intervention Policy (Table 5) to make a decision regarding the process of clearing or developing slums. The number 60 refers to the intermediate stage for determining the intervention policy, before which elimination takes place and after which development intervention is carried out, according to United Nations Human Settlements Program.

\section{Case study application: Ezbet El-Shahatin}

As a result of the rural nature in which the city of Mansoura originated as well as the displacement of the surrounding countryside residents to work and live in the city, a group of random areas appeared either on the outskirts of the city as encroachments on agricultural lands, or in distinctive sites in the heart of the city. Each random area has its distinguishing characteristics which change from one area to another. By studying the area of Ezbet Al-Shahatin, which is one of the most unplanned areas located in the commercial city center

Table 5 Matrix defining the intervention policy (Source: "Tools and Methods of Dealing with Degraded Areas and Slums", Training Course in Urban Planning and Local Economy Development, United Nations Human Settlements Program, 2017)

\begin{tabular}{|c|c|c|c|c|c|}
\hline Value & 2 & 4 & 6 & 8 & 10 \\
\hline Size $\left(\mathbf{m}^{2}\right)$ & $<10000$ & 10001:50000 & 50001:100000 & 100001:200000 & $>200000$ \\
\hline Services - per person & No services & Almost No services & Medium & Almost served & Served \\
\hline good buildings & $0: 20 \%$ & $21: 40 \%$ & $41: 60 \%$ & $61: 80 \%$ & $81: 100 \%$ \\
\hline concrete buildings & $0: 20 \%$ & $21: 40 \%$ & $41: 60 \%$ & $61: 80 \%$ & $81: 100 \%$ \\
\hline residents Ownership & $0: 20 \%$ & $21: 40 \%$ & $41: 60 \%$ & $61: 80 \%$ & $81: 100 \%$ \\
\hline Overcrowding rate & $>5$ persons/ room & 5 persons / room & 4 persons / room & 3 persons / room & 2 persons / room \\
\hline Location and accessibility & Featured & Almost Featured & Medium & Almost Marginal & Marginal \\
\hline Site pollution & Very polluted & Above average & Medium & Below average & Little pollution \\
\hline Land prices & $>5000$ L. E & 3500: 5000 L. E & 2000: 3500 L. E & 500: 2000 L. E & $<500$ L. E \\
\hline Infrastructure Network & No services & Almost No services & Medium & Almost served & Served \\
\hline Total & Directio & emoval & & $A$ tr & levelopment \\
\hline
\end{tabular}


and which lacks many of the basic elements of acceptable human life, this concept with negative features has expanded to include the rest of the patterns of urban, economic and environmental aspects. By studying the region, many negative aspects that must be worked on to limit its development in the future have been identified.

Ezbet El-Shahatin was chosen as a case study aiming at raising the standard of living for its residents. To achieve this goal, a collection of accurate data is required in order to study and evaluate the current situation in the region before beginning to re-plan or clear it. Studies such as the socioeconomic of the population, the distribution of services and facilities, the population density and the condition of networks and buildings therein are required. These operations can be performed with high efficiency using the geographic information systems that were used the urban development (urban, social, and economic). The process is based on the replacement and renewal approach for the development of the region. Such planning project is considered indicative for the implementation of the policy of developing and replacing the slums progressively to improve the living environment (Fig. 3).

Ezbet El-Shahatin is one of the most important unplanned areas located in the commercial heart of the city, which suffers from narrow streets which are inconsistent with the heights of the buildings in addition to the various worn-out buildings. It represents the largest area in the region, and therefore Ezbet El-Shahatin was chosen to be the case study. Ezbet El-Shahatin is in the commercial heart of Mansoura City, which overlooks Sheikh Hassanein Square. (a) Area: 26.7 Acre.

(b) Max. width: $240 \mathrm{~m}$.

(c) Max. length: $430 \mathrm{~m}$.

(d) Border: it is bordered to the north by Mohamed Fathy Street, to the south by Galaa Street, to the east by the School of Agriculture and Dr. Sayed Abu $\mathrm{Al}-$ Enein Street, and to the west by Al Raea Street (Fig. 3).

\section{Field study of Ezbet El-Shahatin area}

Field study of Ezbet El-Shahatin area has been conducted through successive field visits. It was divided into four areas with real estate numbering and characterization according to the forms of urban survey. The output of this data related to the filed research studies was done in 2018/2019 (Fig. 4).

The area was divided into four areas, and the properties were numbered and described according to the urban survey forms.

- First part: the properties were numbered from 1 to 321, the second part was numbered from 1 to 364, the third part was numbered from 1 to 246 , and the fourth part was numbered from 1 to 477 .

\section{Research findings}

The environment and community of Ezbet Al-Shahatin suffer from the absence of many of the basic elements of acceptable human life, which is a major challenge to deal with. The concept of slums is no longer an expression of low urban or structural aspects only; however,

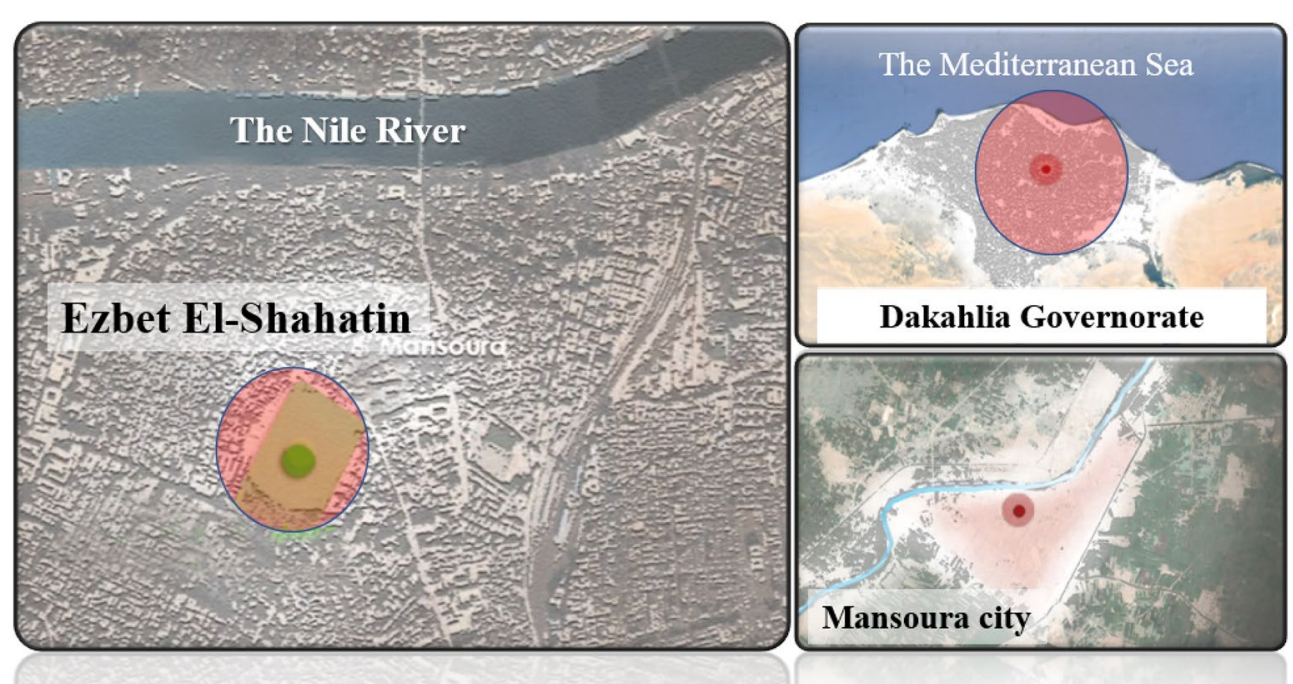

Fig. 3 Ezbet El-Shahatin Site plan 


\begin{tabular}{|c|c|}
\hline apees & Identify Area \\
\hline residential & 2.67714830400285443 \\
\hline $\begin{array}{l}\text { isential } \\
\text { memcial }\end{array}$ & 339.5764622347412 \\
\hline $\begin{array}{l}\text { cosidiential } \\
\text { commectial }\end{array}$ & 513.6749966294615 \\
\hline mmecial & 856.0911978118044 \\
\hline 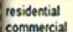 & 215.9332469851669 \\
\hline $\begin{array}{l}\text { residential } \\
\text { commentiat }\end{array}$ & 129.89153944160756 \\
\hline $\begin{array}{l}\text { residential } \\
\text { commetcical }\end{array}$ & 427.768669005162905 \\
\hline resibential & 255.1883378758482 \\
\hline $\begin{array}{l}\text { residential } \\
\text { commer ciat }\end{array}$ & 12565.9573116601193 \\
\hline $\begin{array}{l}\text { rosidential } \\
\text { cormmetcian }\end{array}$ & 421.56663199267177 \\
\hline $\begin{array}{l}\text { residential } \\
\text { commeticial }\end{array}$ & 149.89828254450076 \\
\hline conmmetial & 131.7.78866252567855 \\
\hline commential & 450.7933514253596 \\
\hline 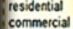 & 1325729505228763 \\
\hline $\begin{array}{l}\text { iesidentital } \\
\text { conmenticis }\end{array}$ & 92.6991483277326 \\
\hline esididential & 98.71159093055414 \\
\hline
\end{tabular}

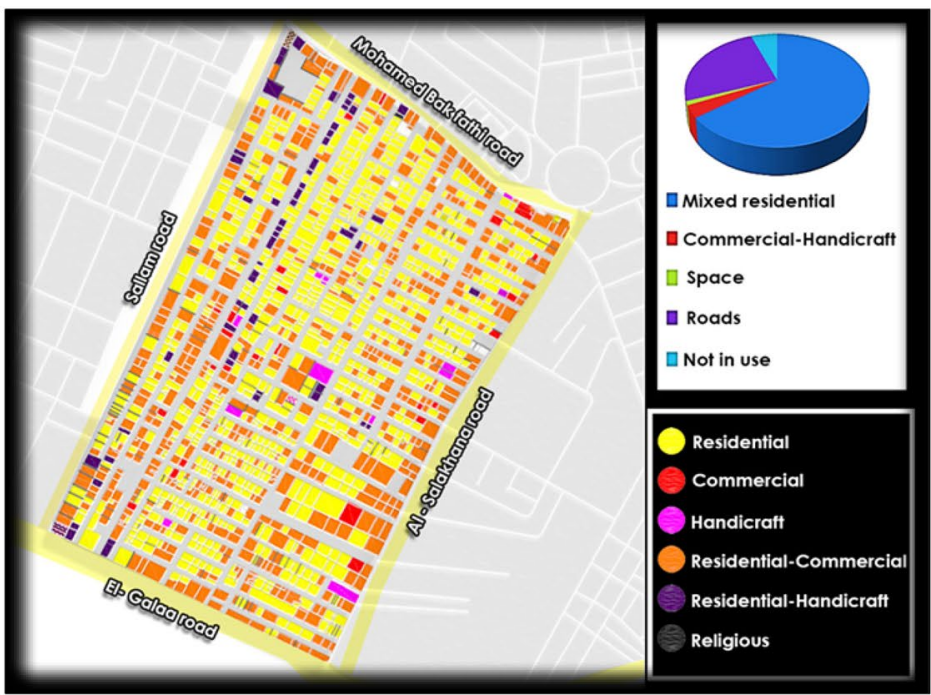

\begin{tabular}{|c|c|}
\hline heights. & IDenoty Atrea \\
\hline $\begin{array}{l}\text { mose then } \\
\text { that floce }\end{array}$ & 676.65830306155142 \\
\hline $\begin{array}{l}\text { move then } \\
\text { sos flose }\end{array}$ & 130.175794655960033 \\
\hline 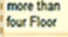 & 465.7166606994272 \\
\hline 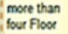 & 162.13150054223575 \\
\hline mese then & 189.521 .59907652088 \\
\hline 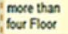 & $18928 s 5007397032$ \\
\hline move then & 22641700126326855 \\
\hline $\begin{array}{l}\text { mose then } \\
\text { tout floce }\end{array}$ & 85 20055955787956 \\
\hline $\begin{array}{l}\text { mese then } \\
\text { fors floce }\end{array}$ & 20.3161689799059 \\
\hline meser inges & 199.765905356555506 \\
\hline $\begin{array}{l}\text { mote then } \\
\text { tos floce }\end{array}$ & 592.00328206845164 \\
\hline $\begin{array}{l}\text { maxe then } \\
\text { tose floce }\end{array}$ & 145 25833602417413 \\
\hline mose then & S02 $5550598659915 \mathrm{SA}$ \\
\hline $\begin{array}{l}\text { mexe then } \\
\text { tose floce }\end{array}$ & 398.4787г269977076 \\
\hline toetson & \\
\hline
\end{tabular}

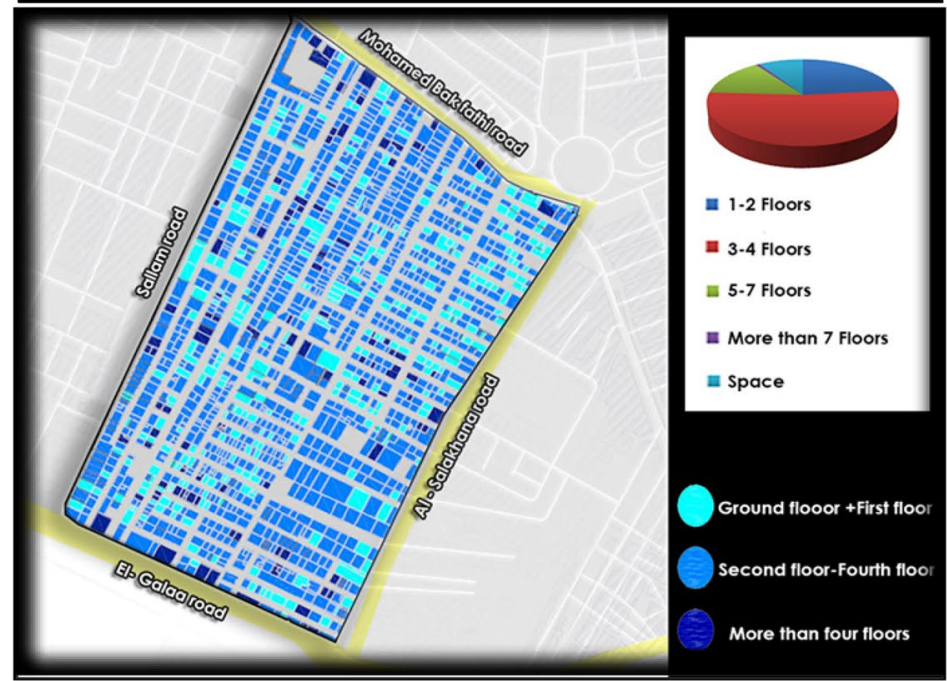

\begin{tabular}{|c|c|}
\hline Hatos & Identity Area \\
\hline bas & $155.1633 \times 1483190205$ \\
\hline boos & 125.842610002450865 \\
\hline midese & 151.92669783402392 \\
\hline $\operatorname{socos}$ & 83.88000005563796 \\
\hline $\operatorname{socos}$ & 7.7.808155680074741 \\
\hline $\operatorname{sos} \alpha$ & 7.92704125682548 \\
\hline midese & $76250 \mathrm{~m} 89343371$ \\
\hline bas & $139.685760697 \times 9996$ \\
\hline goses & $137.1968585 \mathrm{sm} 7$ \\
\hline goos & 80.052565571353 \\
\hline bos & 101, 10308314496437 \\
\hline midse & 111.2021843020435 \\
\hline gases & 26726272383255113 \\
\hline bas & 276.790122860020713 \\
\hline misce & 399268916901714255 \\
\hline bos & 111.82802035535356518 \\
\hline $\operatorname{sosec}$ & $49.785147716 \times 99316$ \\
\hline bors & 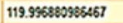 \\
\hline bost & 79.12298986135988 \\
\hline misese & 134.50001565987571 \\
\hline $\operatorname{soses}$ & 21525601502515775151 \\
\hline $\operatorname{sosec}$ & 437.6057869881362 \\
\hline od & 208.51955501428711 \\
\hline misse & 18.02185123939372 \\
\hline
\end{tabular}

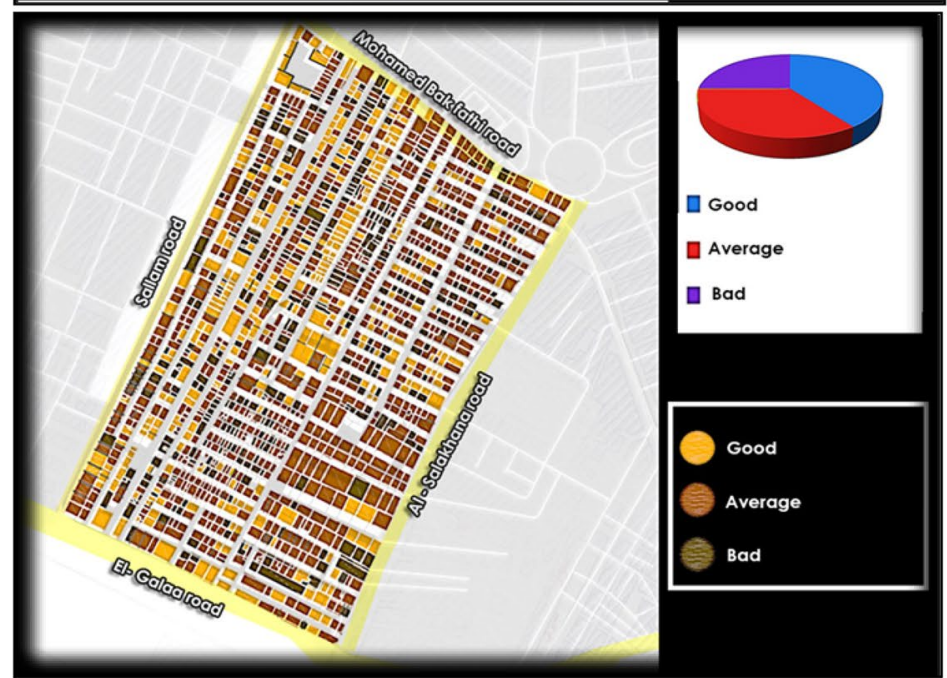

Fig. 4 shows the uses—-heights_condition (good_medium—bad) of the buildings in Ezbet El-Shahatin. Source: The researcher using Arc Map software 
this negative feature concept has expanded to include the rest of the patterns of urban, economic and environmental aspects. By investigating the region, many serious negatives which were found must be confronted to limit their future development. Those negatives are presented in several aspects through the following.

\section{Urban patterns}

- Unplanned area-this region does not follow the basics of urban planning, given that the residents conduct the planning process on their own without the help of specialists. In addition, the urban form of this region varies according to the multiple conditions, such as the location, the way of growth, the network of paths and the properties of buildings. The urban cluster of the region is characterized by a semi-grid structure and narrow streets (Fig. 5).

- The imbalance in the urban structure, where a contrast appears between the planned and random urban fabric of the city.

\section{Land subdivision}

- The Land Division Law provides that the divider leaves a third of the area for streets and gardens while the width of the streets is not less than $10 \mathrm{~m}$ in addition to other requirements (Fig. 5). However, the division of lands in Ezbet Al-Shahatin is often done by the owners without referring to the planners and without considering the requirements stated the division law. Consequently, the streets are narrow, the area of the land is less than what stated by law and the construction runs over the entire space.

\section{Streets}

- Buildings and streets were randomly created in a disorganized manner without direction or supervision.

- Street narrowness and inconsistency with building heights (Fig. 6).

- Streets in the area differ from other planned areas in terms of their widths, condition, and forms.

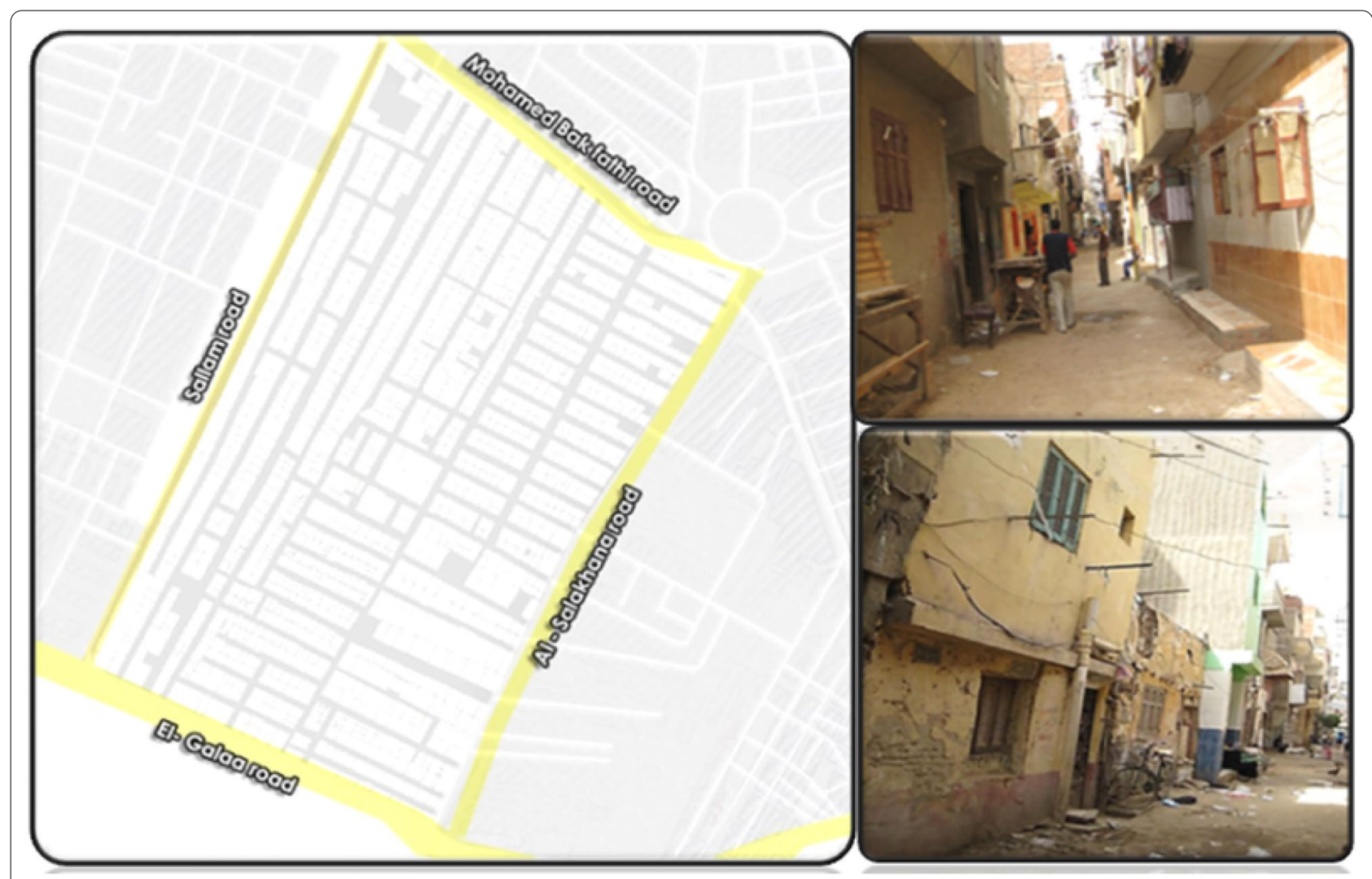

Fig. 5 Showing the urban Patterns and land subdivision 


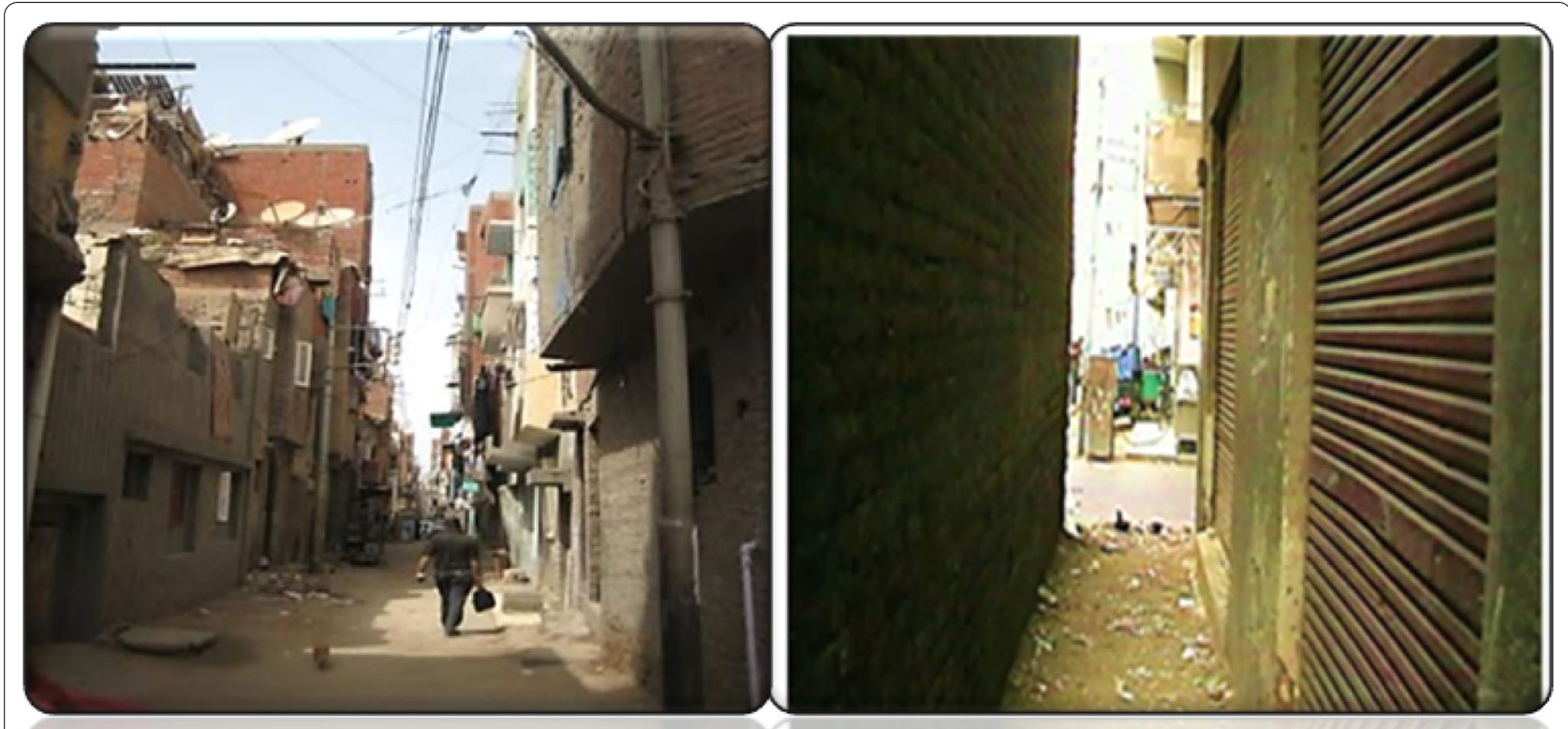

Fig. 6 Showing the Street narrowness and inconsistency with building heights

- Poor condition of the road network and pedestrian paths, which are not suitable for the size of traffic or use in emergency situations.

\section{Buildings}

- Ezbet El-Shahatin is of commercial and residential use, as the area overlooks the commercial downtown areas.

- Many buildings in the area are worn out.

- Building operations take place away from modern systems, where the construction process is done under supervision and based on the instructions of small contractors or craftsmen.

- Engineering and structural weakness in addition to the instability of the buildings, as most of them were rapidly built. Therefore, those buildings are subject to collapse.

- Buildings vary in heights-three and four floors- as most buildings in the region, by $52.6 \%$.

- Most buildings use red bricks and concrete roofs as a basic construction system for the area.

- Some areas suffer from poor construction conditions, especially those built of red bricks with wooden ceilings, or those that have been built using construction waste or mud (Fig. 7).

- The finishing of the facades is almost non-existent, which makes the buildings look poor despite their recent construction.

\section{V.V. Open spaces}

- Ezbet El-Shahatin lacks gardens, green spaces and open areas, in addition to the absence of an outlet for the residents amid these crowded buildings.

\section{Services}

- All slums suffer from the lack of services, which are not commensurate with the size of the population and are less than the level in the official areas. They are characterized by the lack of green spaces, cultural and recreational services, and public buildings.

- The distribution of public services facilities is done at random.

- A lack in the amount and type of health, educational and recreational services.

- Green spaces, cultural, recreational, and administrative services are virtually nonexistent.

- The lack or inefficiency of public utility networks in general.

- The lack of an integrated system for street cleaning and garbage collection in an organized manner from homes and streets. 

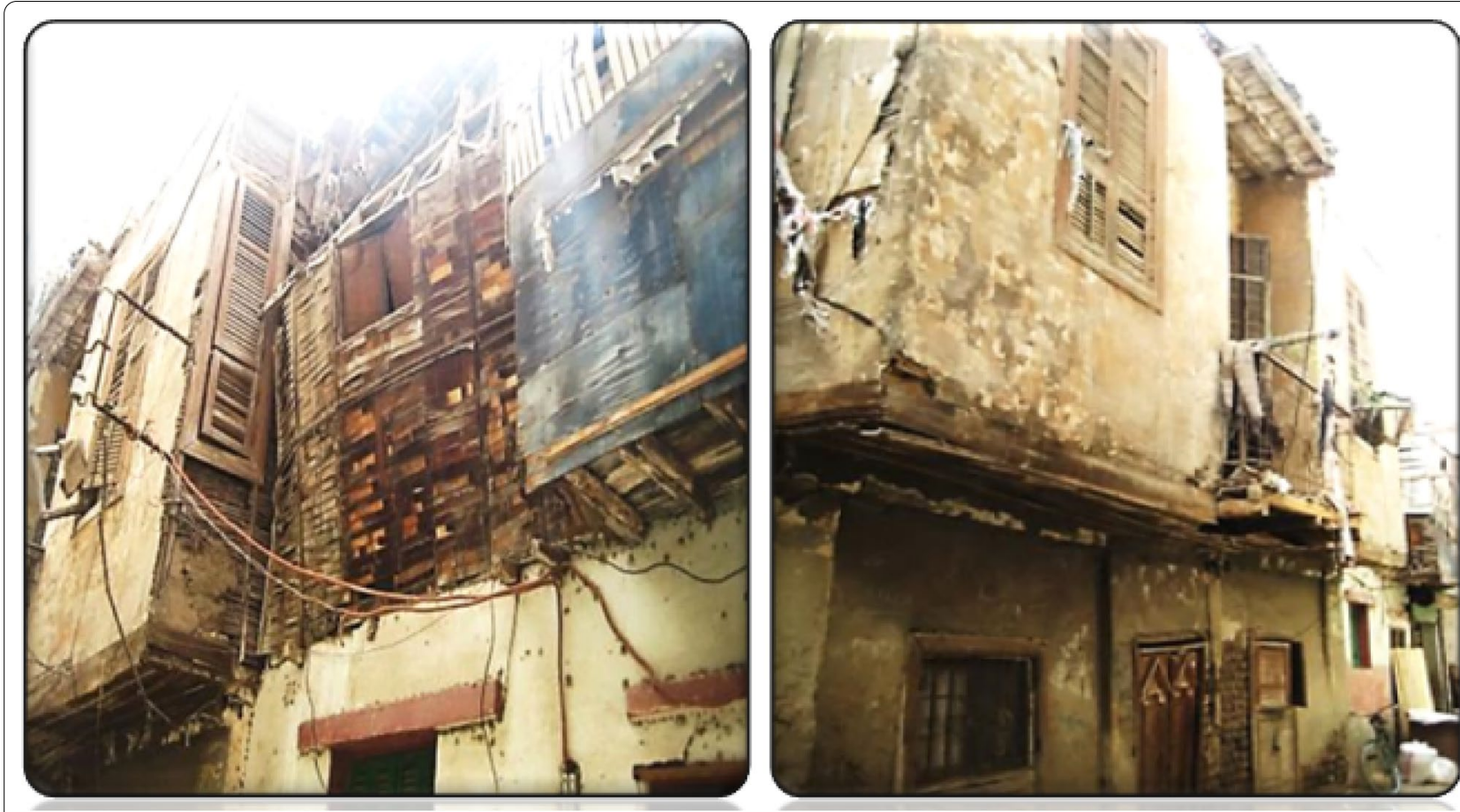

Fig. 7 Some areas suffering from poor construction conditions

\section{Aesthetic aspects}

- The roads are narrow and uneven, and the buildings erected on their sides are bad looking, a terrible residential and structural fusion that denotes a general deterioration of the urban environment. This is a newly established area; however, it is a part that suffocates the city of Mansoura, prevents its growth, and distorts the beauty of nature around it.

\section{Intervention policies in Ezbet El-Shahatin}

The intervention policy definition matrix was applied to the area of Ezbet El-Shahatin to determine the proposed intervention policy which indicates demolition where the criteria of the matrix were applied and the result (56), which is less than (60). Therefore, demolition becomes the proposed approach of development rather than redevelopment as shown below Table 6 .

\section{Techniques proposed to the development of Ezbet El-Shahatin}

Several methods and stratigic techniques of Urban Development could help in the development Ezbet ElShahatin, while putting into consideration the factors and environment that affect that place. It could be planed as in the following (Sorate et al. 2014):
1. Developing a model for integrated urban development in low-income areas that is replicable in other locations.

2. Finding mechanisms to implement the development plan for the study area.

3. Studying and evaluating the current conditions in the region and identifying problems and development possibilities.

4. Working to solve the constructional problems that have been identified (overlapping land uses-lack of public services-narrow and irregular road network-lack of clarity of the hierarchy in the road network).

5. Proposing plans to achieve sustainable urban and environmental development in the region.

6. Providing suitable sites for current and future public services.

7. Establishing urban development regulations and proposed building systems in accordance with the provisions of Law No. 119 of 2008.

8. Defining the stages of upgrading and development.

9. Linking the area with the immediate areas and the general structure of the city of Mansoura.

10. Setting a database about the region and its development plan.

11. Identifying investment sites and projects that contribute to increasing the economic activity. 


\section{Proposed strategic development plan for Ezbet El-Shahatin}

- Based on the above mentioned, dealing with the region is based on two main axes:

1. The first axis: the replacement and renewal approach are used to develop Ezbet El Shahateen, by transferring the residents to temporary government housing until the complete demolition of old houses, infrastructure construction and reconstruction are completed. Then, the residents are re-housed.

2. The second axis: the development of the local community and its upgrading in all fields (socially, health, economically, educationally) so that it is qualified enough to adapt to the new environment through the implementation of an integrated development program that begins during the period of residents transfer to enable implementing the detailed plan for the area and continue after their return to permanent residence, based on the questionnaire for monitoring community needs.

- Resources and funding

The stage of preparing the implementation program:

1. The project implementation program is prepared based on an estimate of the time limit of the project components

2. The time required for preparing the necessary executive documents is determined, such as the establishment of the institutional framework representing the legally authorized personnel to deal with private land ownership, the establishment of the project management unit, and community development activities.

3. Specifying the time and the mechanisms required to follow up the implementation of the work.

4. Arrangements for business delivery and operation are determined.

Financial plan preparation stage:

The financial plan of the project is prepared with a statement of:

1. An estimate of the current and future prices of land and residential and non-residential units.

2. The available funding from grants, social benefits, loans, and credit facilities.

3. The cost of development including an estimate of the:

- Cost of housing the people until the completion of development work (if necessary).
- Value of removal and site clearance.

- Compensation required.

- Value of construction works.

- Cost of the proposed community development work.

\section{Phases of implementation}

The idea of a development plan relies on preparing a sustainable plan for the region and setting planning and structural requirements to redistribute the uses so that the region becomes a commercial residential area (Abbott et al. 2002). According to the distinguished location and in line with the future vision of Dakahlia Governorate, the area has been planned with sustainability as the main objective of development by taking into account environmental considerations (space design, energy and water efficiency, resource efficiency, the quality of the internal environment of the building, and the impact of the building as a whole on the environment) at each stage of the building process (design, implementation, operation). The development project is implemented in three phases.

1. First Phase. The first phase covers an area of 8 acres that includes ( 97 residential buildings -1146 housing units - 5730 people - a gas station-green areasparking places). The following map shows the proposed plan for that phase in accordance with the provisions of the laws regulating the urban planning process and Law No.119 of 2008 (Fig. 8).

2. Second Phase. The second phase covers an area of 9.5 acres that includes (37 residential buildings -564 housing units -2820 people). It also includes all services that must be provided to the residents of slums, considering the future time, and specifying their locations and the required areas within the region (school-hospital-mosque-Child custody .... etc. form (Fig. 8).

3. Third Phase. The third phase covers an area of 9.4 acres that includes (116 residential buildings-1578 housing units-7890 people—a solar power station) (Fig. 8).

\section{Expected results from implementation of the proposed strategic development plan for Ezbet El-Carama (Previously El-Shahatin)}

The upgrading process includes raising environmental, economic, and social development which becomes clear in the following table (Table 7): 


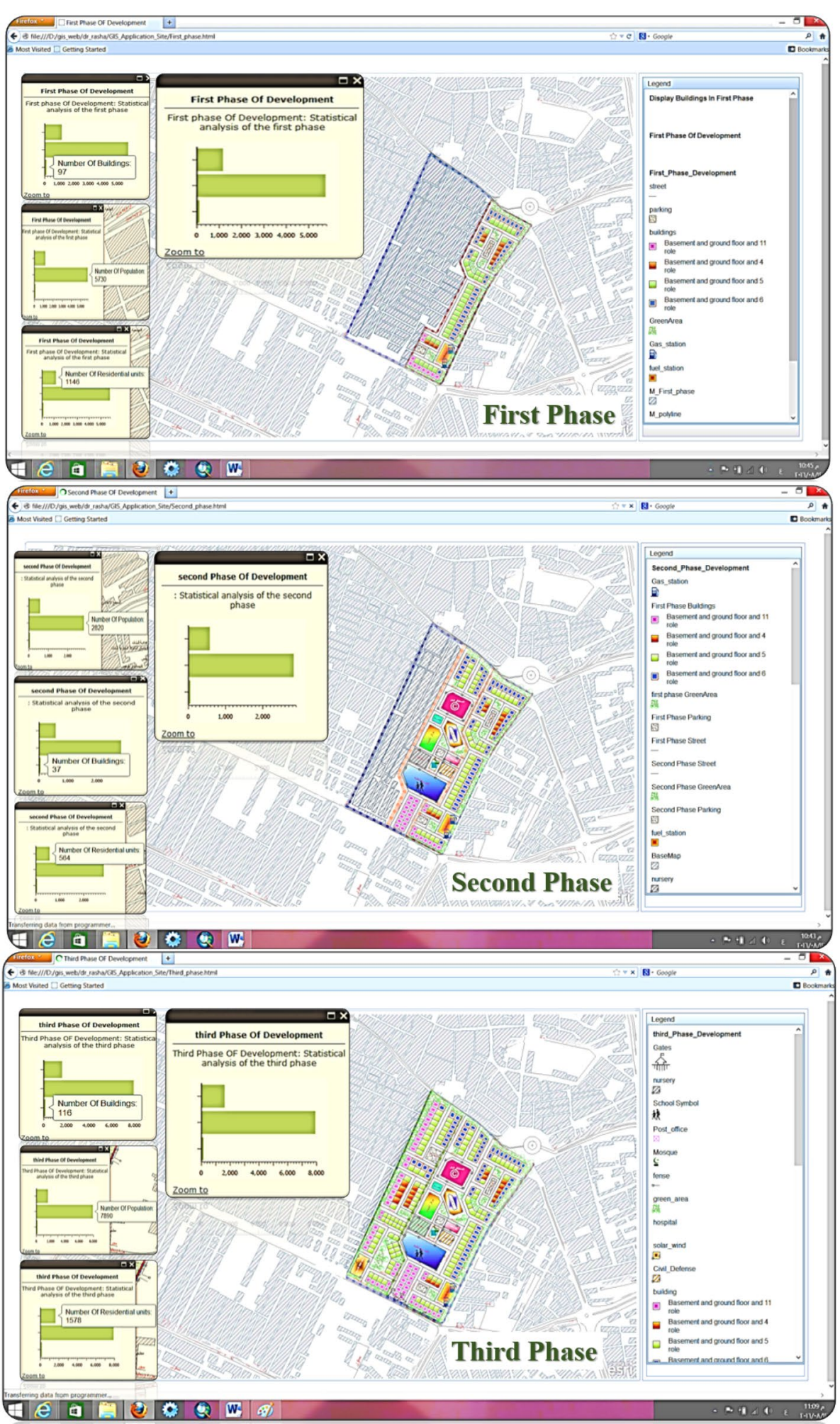

Fig. 8 Three Phases of new sustainable urban development for Ezbet El-Carama (Previously El-Shahatin) 
Table 6 Ezbet El-Shahatin Matrix defining the intervention policy (Source: Adapted researcher "Tools and Methods of Dealing with Degraded Areas and Slums", Training Course in Urban Planning and Local Economy Development, United Nations Human Settlements Program, 2017)

\begin{tabular}{|c|c|c|c|c|c|}
\hline Value & 2 & 4 & 6 & 8 & 10 \\
\hline Size $\left(m^{2}\right)$ & $<10000$ & 10001:50000 & 50001:100000 & $100001: 200000$ & $>200000$ \\
\hline Services - per person & No services & Almost No services & Medium & Almost served & Served \\
\hline good buildings & $0: 20 \%$ & $21: 40 \%$ & $41: 60 \%$ & $61: 80 \%$ & $81: 100 \%$ \\
\hline concrete buildings & $0: 20 \%$ & $21: 40 \%$ & $41: 60 \%$ & $61: 80 \%$ & $81: 100 \%$ \\
\hline residents Ownership & $0: 20 \%$ & $21: 40 \%$ & $41: 60 \%$ & $61: 80 \%$ & $81: 100 \%$ \\
\hline Overcrowding rate & $>5$ persons/ room & 5 persons / room & 4 persons / room & 3 persons / room & 2 persons / room \\
\hline Location and accessibility & Featured & Almost Featured & Medium & Almost Marginal & Marginal \\
\hline Site pollution & Very polluted & Above average & Medium & Below average & Little pollution \\
\hline Land prices & $>5000$ L.E & 3500: 5000 L.E & 2000: 3500 L. E & 500: 2000 L. E & $<500$ L. E \\
\hline Infrastructure Network & No services & Almost No services & Medium & Almost served & Served \\
\hline Total & Directio & emoval & & tren & ent \\
\hline
\end{tabular}

Table 7 Principles of sustainable urban design for Ezbet El-Shahatin

\section{Principles of sustainable urban design for Ezbet El-Shahatin}

Environmental Creating an overlap between the green spaces and buildings in the construction and find adequate areas of green fabric, which includes coordination of streets, gardens, parks, and pedestrian paths (In our previous study Ragheb and EL-Ashmawy 2020)

Providing appropriate housing which is characterized by distinct architectural and urban features in buildings and squares, and providing work, housing, entertainment, and services areas within the appropriate walking distance for the people

Achieving urban development controls and proposed building systems in accordance with the provisions of Law 119 of 2008. (Building heights, street widths, building uses ....)

Linking the developed area with its neighboring areas and the general structure of the city of Mansoura

Social Developing and upgrading the local community in all fields (socially, healthily, economically, educationally) so that it is qualified to adapt to the new environment through the implementation of an integrated development program that begins during the period of population transfer to enable implementing the detailed plan for the area and continues after returning to permanent residence Setting realistic timetables and resources for development plans in addition to clarifying the roles and responsibilities of each of the implementing and supervising authorities in order to avoid obstacles and functional overlaps

Implementing social care projects for the population, providing means of technical education, eradicating illiteracy, computer workshops, health awareness campaigns and educational trips for young people

Communicating with the residents of the area to get acquainted closely with their needs, informing them of the various plans and activities and solving their problems

Providing the main services such as natural gas, potable water, a sewage system, electricity, and a system for collecting garbage from homes

Providing some services such as a gym, a number of facilities such as a hospital, a nursery, a social center, and a sufficient number of schools

Continuous monitoring of the proposed plans for implementation, as well as continuous evaluation of the implemented plans so that the situation can be modified in proportion to the changes taking place

Economic Paying attention to the economy. Therefore, sustainable societies are reasonably economic societies that ensure that services are provided to all residents at the same level and costs to ensure justice

Identifying sites and investment projects that contribute to increasing economic activity to create different job opportunities to reduce poverty and unemployment

Re-housing residents to the area next to their work and schools after the development process is completed in order to maintain the network of social relations and to provide appropriate environmental, health and professional conditions so that the middle-class population shifts from the state of consumption only to the state of consumption and production

The means of transportation does not constitute a burden on the residents because the area is close to the main roads in the heart of Mansoura

\section{Successful case by using the intervention policy definition matrix}

- The intervention policy definition matrix was applied to the area of Zinhum Housing to determine the proposed intervention policy which indicates demolition where the criteria of the matrix were applied and the result is (32), which is less than (60). Therefore, demolition has become the development approach, not redevelopment, as shown below in Table 8. 
Table 8 Zinhum Housing Matrix defining the intervention policy ( Source: Adapted researcher "Tools and Methods of Dealing with Degraded Areas and Slums", Training Course in Urban Planning and Local Economy Development, United Nations Human Settlements Program, 2017)

\begin{tabular}{|c|c|c|c|c|c|}
\hline Value & 2 & 4 & 6 & 8 & 10 \\
\hline Size $\left(m^{2}\right)$ & $<10000$ & 10001:50000 & 50001:100000 & 100001:200000 & $>200000$ \\
\hline Services - per person & No services & Almost No services & Medium & Almost served & Served \\
\hline good buildings & $0: 20 \%$ & $21: 40 \%$ & 41: $60 \%$ & $61: 80 \%$ & $81: 100 \%$ \\
\hline concrete buildings & $0: 20 \%$ & $21: 40 \%$ & 41: $60 \%$ & $61: 80 \%$ & $81: 100 \%$ \\
\hline residents Ownership & $0: 20 \%$ & $21: 40 \%$ & 41: $60 \%$ & $61: 80 \%$ & $81: 100 \%$ \\
\hline Overcrowding rate & $>5$ persons/ room & 5 persons / room & 4 persons / room & 3 persons / room & 2 persons / room \\
\hline Location and accessibility & Featured & Almost Featured & Medium & Almost Marginal & Marginal \\
\hline Site pollution & Very polluted & Above average & Medium & Below average & Little pollution \\
\hline Land prices & $>5000$ L. E & 3500: 5000 L. E & 2000: 3500 L. E & 500: 2000 L. E & $<500$ L. E \\
\hline Infrastructure Network & No services & Almost No services & Medium & Almost served & Served \\
\hline Total & Directio & moval & & A trer & opment \\
\hline
\end{tabular}

- Zinhum Housing area in Sayeda Zeinab neighborhood constitutes a unique case in dealing with poor and informal areas. Residents of other areas always stress that Zinhum housing is the ideal model they would like to develop their area in the same way. Zinhum area was developed, and the people re-housed in the same location. Also, there was cooperation and fruitful partnerships and a distribution of roles between different parties from government agencies, civil society, the private sector and businessmen in the development process, which rarely happens.

- Before development, the area consisted of a group of wooden shacks in a rather degraded condition, environmentally and socially (Fig. 1). However, many of these shacks were shelters built by the Cairo Governorate for the people whose houses were demolished as a temporary shelter until the governorate is building alternative housing for them. The population of Zinhum district was about 20,000 people, representing about 4,000 families. The total area is 50 acres.

- The residential unit area of the project is $67 \mathrm{~m}^{2}$. The residential building contains 12 apartments in the first two phases, raised to 14 apartments in the third phase, taking into account that the construction ratio does not exceed $30 \%$.

- First, a case study and population inventory were carried out by the Red Crescent Society. Then, the area was divided into three zones to be worked on, respectively. At each stage, the residents were transferred to temporary government housing in $\mathrm{Al}$ Nahda buildings in Al-Salam City or Al-Mothallath buildings in Helwan until the complete demolition of the old houses, the construction of infrastructure and reconstruction, and then the residents are re-housed, Figs. 9, 10.

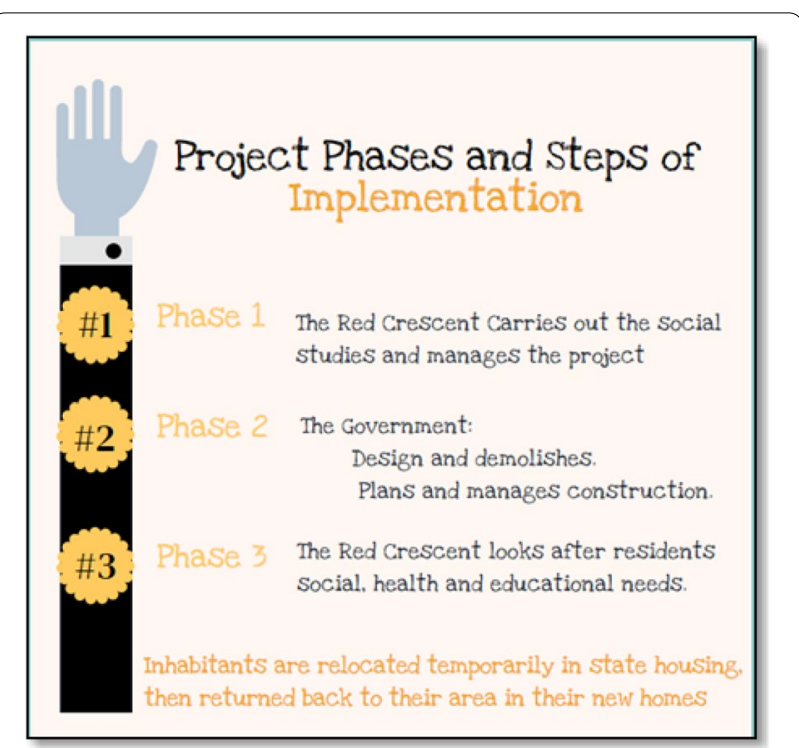

Fig. 9 Zinhum Housing Project Phases and steps of implementation

- The project relied on two main axes, namely:

- Social development in the field of education, health, and the cultural level of the population.

- The total demolition of the shacks and random buildings, and the reconstruction of modern buildings through better urban planning that takes into account the required health, environmental and humanitarian specifications and allows the presence of green spaces.

- Resources and funding:

- The project adopted a multi-source financing mechanism, which included government agencies, NGOs and businessmen. 


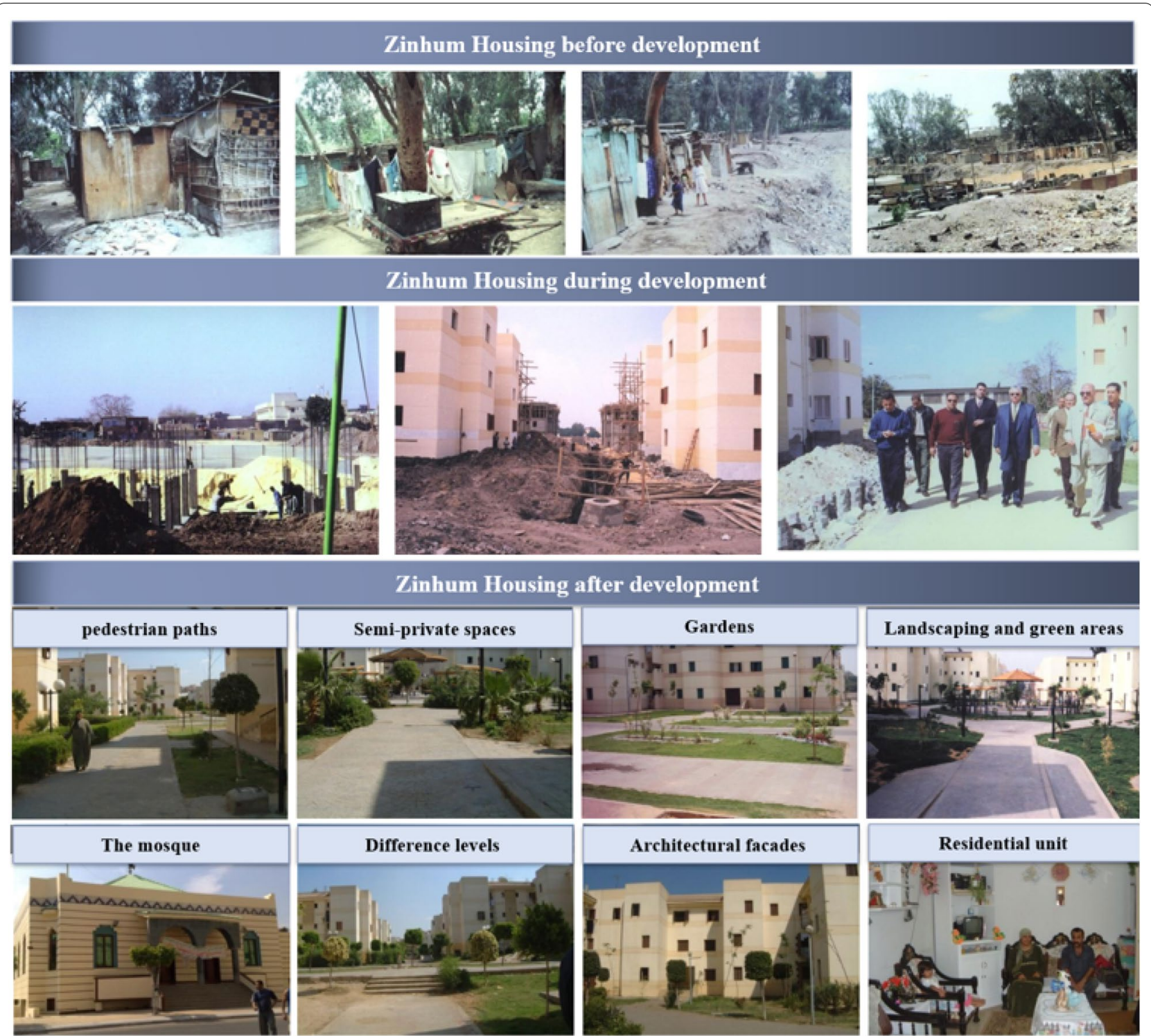

Fig. 10 Zinhum Residence before, during and after development. ( Source: Adapted researcher "Tools and Methods of Dealing with Degraded Areas and Slums", Training Course in Urban Planning and Local Economy Development, United Nations Human Settlements Program, 2017)

- The government agencies represented in Cairo Governorate financed the removal operations, site preparation and the costs of supplying basic facilities for the three phases of the project.

- The Egyptian Red Crescent Society has collected and managed funding (grants for businessmencontractors-NGOs) to implement the construction of residential buildings and service buildings.

- The government, represented in Cairo Governorate, carried out the urban planning and architectural design through one of the consulting offices (United Consultants), which donated the design of most of the project's phases free of charge as a contribution from the office to the success of the project.

- The governorate also provided temporary housing and supervised construction, while contracting companies carried out building according to the governorate's plan.

This project is an important development in the way of thinking of both government agencies and civil society, and the adoption of important concepts for the process of urban development and reconstruction, both from 
the relative participation of the local community, development activities and re-housing the people in the same place. This model is believed to be successful because it maintains the social network of the people of the area, and is interested in re-housing the residents next to their businesses and schools after the development process, which is rare in dealing with the problem of informal and deteriorating housing. In the end, the Zeinhom housing project provides a positive experience in the state's handling of informal construction and re-housing residents in their original places after development.

\section{Conclusion}

- The primary goal of developing slums is to raise the standard of living for their residents. To achieve this goal, accurate data must be collected to study and evaluate the status of the region before beginning to re-plan, develop, or clear it. The necessary analytical studies of social and economic data of the population, the distribution of services and facilities, the condition road networks, streets, and buildings are conducted.

- When re-planning slums, consideration shall be given to applying planning and design standards in accordance with the provisions of laws and regulations.

- When re-planning slums, consideration is given to the availability of all the services that must be provided to the residents considering the future extension within the area (school-hospital-mosquekindergarten-ambulance-youth center-post office-civil defense office-commercial mall-Gas station-solar power station).

- The planning process is concerned with setting a set of strategies to achieve several specific goals for the targeted sustainable development. Planning is the outcome of a set of specific efforts to achieve collective decisions issued by decision makers to reach comprehensive goals, according to the future expectations of the available resources, whether economic, social or environmental, to form a clear strategy in a specific period of time, based on what is currently available, and what can be achieved in the future to improve all economic, social and environmental aspects, in order to raise the level of performance in all these areas.

- The implementation of a sustainable development policy for slum housing requires setting timelines and realistic resources for the development plans in addition to clarity of roles and responsibilities for each of the implementing and supervising bodies on the sustainable development policy, to avoid obstacles and functional overlaps. In addition, it is necessary to constantly monitor the proposed plans and the current plans besides the continuous evaluation of the implemented plans so that the situation can be adjusted in proportion to the changes and lessons learned. Finally, the development of slums should not conflict with preserving the materials and natural resources of the environment.

- The main determinants of the development process are, in their entirety, the outlines of the proposed policy of slums. These determinants include the outlook in light of a number of unknown factors that can be drawn from previous experiences that these regions have gone through. Finally, it can be said that the planning strategy for slums should achieve the development goals of the country, to help achieve a sustainable development to serve the present and future generations' welfare.

Author's contributions

Both the authors read and approved the final manuscript.

\section{Competing interests}

Many thanks for the President of Delta University for Science \& Technology and my colleague that support methrough my research work of my manuscript.

Received: 14 April 2021 Accepted: 2 August 2021

Published online: 09 August 2021

\section{References}

Abbott J (2002) A method-based planning framework for informal settlement upgrading. Habitat Int 26(3):317-333. https://doi.org/10.1016/S01973975(01)00050-9

Atlaw H (2014) Slum Redevelopment in Addis Ababa: how can it become sustainable? Int J Sci Res 3(9): 2387-2393. https://www.ijsr.net/archive/ v3i9/UOVQMTQ2MDk=.pdf

Bah EM, Faye I, Geh ZF (2018) Slum upgrading and housing alternatives for the poor. In: Housing market dynamics in Africa. Palgrave Macmillan, London, pp. 215-253. https://doi.org/10.1057/978-1-137-59792-2_6

Cretan R, O'brien T (2019) 'Get out of Traian Square!': roma stigmatization as a mobilizing tool for the far right in Timişoara, Romania. Int J Urban Reg Res 43(5):833-847. https://doi.org/10.1111/1468-2427.12626

Ezeh A, Oyebode O, Satterthwaite D, Chen YF, Ndugwa R, Sartori J et al (2017) The history, geography, and sociology of slums and the health problems of people who live in slums. The Lancet 389(10068):547-558. https://doi. org/10.1016/S0140-6736(16)31650-6

Gans HJ (1959) The human implications of current redevelopment and relocation planning. J Am Inst Plann 25(1):15-26. https://doi.org/10.1080/01944 365908978294

Jones P (2017) Formalizing the informal: Understanding the position of informal settlements and slums in sustainable urbanization policies and strategies in Bandung, Indonesia. Sustainability 9(8):1436. https://doi.org/ 10.3390/su9081436

Khalifa MA (2011) Redefining slums in Egypt: Unplanned versus unsafe areas Habitat Int 35(1):40-49. https://doi.org/10.1016/j.habitatint.2010.03.004 
Khalifa MA (2015) Evolution of informal settlements upgrading strategies in Egypt: from negligence to participatory development. Ain Shams Eng J 6(4):1151-1159. https://doi.org/10.1016/j.asej.2015.04.008

Lutzoni L (2016) In-formalized urban space design. Rethinking the relationship between formal and informal. City Territ Archit 3:20. https://doi.org/10. 1186/s40410-016-0046-9

McCombie J, Thirlwall AP (2016) Economic growth and the balance-of-payments constraint. Springer

Mukhija V (2001) Upgrading housing settlements in developing countries. Cities 18(4): 213-222. www.elsevier.com/locate/cities

Parham E (2012) The segregated classes: spatial and social relationships in slums. In: Proceedings of the 8th International Space Syntax Symposium, Santiago: Pontificia Universidad Católica, vol. 8150, pp. 01-19

Pelz PF, Friesen J, Hartig J (2019) Similar size of slums caused by a Turing instability of migration behavior. Phys Rev E 99(2):022302. https://doi.org/ 10.1103/PhysRevE.99.022302

Ragheb AA, EL-Ashmawy RA (2020) Urban waterfront development for designing space in coastal cities. Int J Sustain Dev Plan 15(3):345-352. https:// doi.org/10.18280/ijsdp.150311

Ragheb G, El-Shimy H, Ragheb A (2016) Land for poor: towards sustainable master plan for sensitive redevelopment of slums. Proc Soc Behav Sci 216:417-427. https://doi.org/10.1016/j.sbspro.2015.12.056

Rankey K (2018) A framework for creating positive change: solutions for slum important through local empowerment. Michigan Sociol Rev 32: 148-169. https://www.jstor.org/stable/26528600

Shepherd DA, Parida V, Wincent J (2020) Entrepreneurship and poverty alleviation: the importance of health and children's education for slum entrepreneurs. Entrepreneurship Theo Pract 1042258719900774. https:// doi.org/10.1177/1042258719900774

Somsook B (2009) Land for housing the poor-by the poor: experiences from the Baan Mankong nationwide slum upgrading programme in Thailand. Environ Urbanization 21(2):309-329. https://doi.org/10.1177/0956247809 342180

Sorate RR, Alka D et al (2014) Slum rehabilitation with fast track techniques. IOSR J Mech Civil Eng 11(3):27-32. https://doi.org/10.9790/1684-11382 732

UN-HABITAT (2003a) Slums of the world: the face of urban poverty in the new millennium? Monitoring the Millennium Development Goal, Target 11-World-wide Slum Dweller Estimation

UN-HABITAT (2003b) The Challenge of Slums, Global Report on Human Settlements 2003. Earthscan Publications Ltd for and on behalf of the United Nations Human Settlements Programmer (UN-Habitat)

UN-Habitat (2015) Informal Settlements. UN-Habitat, New York, NY, USA, pp. $1-8$

Young AF (2016) Adaptation actions for integrated climate risk management into urban planning: a new framework from urban typologies to build resilience capacity in Santos (SP). City Territ Archit 3:12. https://doi.org/10 1186/s40410-016-0042-0

\section{Publisher's Note}

Springer Nature remains neutral with regard to jurisdictional claims in published maps and institutional affiliations.

\section{Submit your manuscript to a SpringerOpen ${ }^{\odot}$ journal and benefit from:}

- Convenient online submission

- Rigorous peer review

- Open access: articles freely available online

- High visibility within the field

- Retaining the copyright to your article

Submit your next manuscript at $\boldsymbol{\text { springeropen.com }}$ 